\title{
Prosthetic heart valves: Difficult to make something simple
}

\author{
Didier Lapeyre, MD, ${ }^{\mathrm{a}}$ Rolland Siegel, BA, ${ }^{\mathrm{b}}$ Lawrence Scotten, DiplT, ${ }^{\mathrm{c}}$ Bas de Mol, MD, PhD, ${ }^{\mathrm{d}, \mathrm{e}}$ and \\ Walter Dembitsky, $\mathrm{MD}^{\mathrm{e}}$
}

\section{"Science without conscience is just ruin of the soul." -François Rabelais, physician and writer, Gargantua, $1534^{1}$}

From the early 1960 s to the late 1990 s, prosthetic heart valve designs were improved through intense scientific and clinical feedback. Mechanical heart valves, however, still require warfarin-based anticoagulation, whereas longterm durability remains a concern for bioprosthetic heart valves, particularly in young adults and children. Thus the current patient age guidelines for tissue versus mechanical valve implants typically specify recipient ages older than 65 years for tissue valves and younger than 65 years for mechanical valves.

Recent meta-analyses have shown that overall and eventfree survivals are similar for patients receiving mechanical and biologic aortic valves. ${ }^{2,3}$ Selection of a valve device is therefore based on a patient's individual life expectancy, ability to take anticoagulants, lifestyle, risk of bleeding, and risk of reoperation. Operative mortality with conventional surgery is low, even in octogenarians, and outcomes at 10 to 15 years and longer are satisfactory. A recent study of 1000 minimally invasive aortic valve replacements reported on a large subgroup of elderly patients ( $>80$ years) with an operative mortality of $1.7 \%$, a median hospital stay of 8 days, and an actuarial survival at 5 years of $84 \%{ }^{4}$

Commercially available valves are still based on concepts largely unchanged from the 1970s and 1980s, with unmet needs for more durable tissue valves and less thrombogenic mechanical valves. These needs are urgent worldwide for patients younger than 65 years. In particular, the need is greatest for juveniles and young adults in emerging countries and for those requiring mitral valve replacement. ${ }^{5}$ Sadly, efforts to achieve these high-priority goals seem largely to have ceased, perhaps because of short-term financial considerations. This situation is even more paradoxic now that advanced techniques in fluid mechanics and molecular biology have identified, analyzed, and quantified causes of the thrombogenic potential of current mechanical valves. Indeed, considerable

\footnotetext{
From Consultant, ${ }^{\mathrm{a}}$ Chaignes, France; Consultant, ${ }^{\mathrm{b}}$ Oswego, Ore; ViVitro Systems Inc, ${ }^{c}$ Victoria, British Columbia, Canada; the Department of Cardiothoracic Surgery, ${ }^{\mathrm{d}}$ Academic Medical Center, University of Amsterdam, The Netherlands; and Sharp Memorial Hospital, ${ }^{\text {e }}$ San Diego, Calif.

Address for reprints: Didier Lapeyre, MD, 30 rue du Val du Puits, 27120 Chaignes,

France (E-mail: didier-lapeyre@wanadoo.fr).

J Thorac Cardiovasc Surg 2010;139:1371-3

$0022-5223 / \$ 36.00$

Copyright $(\underset{2}{ } 2010$ by The American Association for Thoracic Surgery

doi:10.1016/j.jtcvs.2010.02.026
}

evidence has become available on pathologic kinematics at valve opening and closure, ${ }^{6}$ nonphysiologic flow patterns, vortex shedding, turbulence, abnormal flow (separation, stagnation, deceleration), energy loss, squeeze flow, microbubble formation, solid emboli, and vapor cavitation, leading to improved understanding of the link between traumatic forces applied to blood elements, activation of the coagulation cascade, and thromboembolic complications. ${ }^{7,8}$ Moreover, it has been demonstrated that these functional liabilities can be substantially reduced by improvements in valve design and that a durable mechanical bioprosthesis not requiring lifelong anticoagulation may be within reach. ${ }^{9,10}$

Instead, creative industrial energy has focused on catheterbased valve delivery systems to implant devices currently applicable to a small number of patients needing heart valve replacement. The recent article by Mack, ${ }^{11}$ "Fool Me Once, Shame on You; Fool Me Twice, Shame on Me! A Perspective on the Emerging World of Percutaneous Heart Valve Therapy," stimulated great interest in this subject.

There is no doubt that patients prefer less invasive procedures and that a quest for better quality of life encourages adoption of novel medical devices. Heart valve replacement is a lifesaving procedure, however, and "surgery [is] an act of authority on destiny," as René Leriche put it. ${ }^{12}$ Prosthetic heart valves must satisfy stringent technical requirements in terms of safety and efficacy. Despite sophistication of delivery technology, it is quite challenging for catheter-based valve therapy to conform to these requirements. At the same time, it is important to overcome traditional medical conservatism, as ironically described by C. Walton Lillehei in his "seven steps of innovation." 13 This ethical dilemma is exacerbated when financial interests are involved. The absolute criterion should therefore remain that the ultimate benefit to the patient should be "here and now." This leads to 3 crucial questions regarding applicability of transcatheter valve therapy: (1) Can it be done? (2) Should it be done? (3) How can it best be done? Of these 3 phases of technologic evolution, transcatheter valves appear to be entering phase 2 , whereas traditional valve replacement has been in phase 3 for many years.

Many patients with end-stage severe aortic stenosis are not referred for surgery ostensibly because of advanced age or major comorbidity. These patients are often left with suboptimal strategies, such as balloon valvuloplasty. To provide a better therapeutic alternative for these highrisk patients with otherwise inoperable disease, percutaneous catheter-borne valve technology was introduced.

Although this option is rapidly developing, there are growing concerns about its extension to patients at lower risk. In an 
aging population, the number of patients with severe aortic stenosis and reduced life expectancy is increasing. It has been established that at least 1 of every 3 patients with severe aortic stenosis has no symptoms. In the absence of symptoms, the management of these patients is challenging. Frequently, they are not offered surgery because mortality and the yearly risks of prosthetic valve complications are greater than the yearly risks of watchful waiting. Without aortic valve replacement, their survival is favorable: $99 \%, 98 \%$, and $93 \%$ at 1,2 , and 5 years, respectively. ${ }^{14}$ Current practice guidelines do not recommend surgery for these patients, who may remain free of symptoms for many years. Approximately a third of all patients with asymptomatic aortic stenosis show symptoms within 2 years, however, and the prognosis may worsen significantly when symptoms develop. It has been shown that only a minority of those with potentially operable aortic valve stenosis undergo surgery. As recent findings indicate, however, octogenarians may live a lifespan comparable to that of the normal population after biologic aortic valve replacement. ${ }^{15}$

In Europe, 2 catheter-delivered valves have received CE approval. In the United States the PARTNER-USA trial is under way comparing outcomes for the Edwards-SAPIEN transcatheter-delivered valve with those of standard aortic valve replacement in high-risk patients and with those of medical therapy, including aortic valvuloplasty, for patients who are not surgical candidates. Study candidates must be selected by 2 surgeons and 1 cardiologist. Interestingly, patients who are offered surgery but decline are excluded. A similar randomized study of the percutaneous CoreValve delivery system is expected to begin soon. When mortality and clinical outcomes of transcatheter valves compare favorably with those of medical therapy alone or conventional surgery, there is no doubt this specific growing population of elderly, high-risk patients could be candidates for that new therapeutic option.

Potential extension of transcatheter valve implantation to lower risk patients with extended life expectancies along a path similar to that observed with coronary stenting deserves, however, the following observations. First, coronary and vascular stents were initially introduced in the clinical arena for the easiest cases. Subsequently, some interventionalists extended use to multivessel disease, bifurcations, left main disease, renal and carotid arteries, and so on. Reports of restenosed lesions encouraged adoption of new stent models before evidence of long-term efficacy. This "earn-while-you-learn" aberration eroded traditional evidence-based decision making. Currently, transcatheter valve replacement is only proposed for high-risk patients otherwise restricted to medical therapy alone.

Second, coronary stents and prosthetic heart valves are passive devices. Unlike stents, however, prosthetic heart valves must withstand wide ranging dynamic stress and cyclic loading for many years. Valve substitutes must also comply with the stringent requirements of the international norm (ISO 5840) that mandates a systematic risk analysis and risk reduction to the very minimum.

To our knowledge, this regulatory issue has not as yet been resolved for transcatheter-inserted valves. Recent US Food and Drug Administration Advisory Panel comments are pertinent. "In contrast, the developing field of percutaneous heart valve insertion demands innovative trial designs to address difficult new concerns. These concerns include defining target populations; establishing the correct risk/benefit ratio based on a new balance between safety and effectiveness perceived for the reduction in surgical risk; and choice of appropriate endpoints for assessment. Although innovative trial design may be necessary in certain cases of new technology, the most appropriate study design remains a randomized controlled trial as the gold standard.,"16

There is a tacit assumption that durability for catheterdelivered tissue valves will be similar to that of current, conventional tissue valves, but this has yet to be determined. For the standard stented porcine and pericardial valve, durability appears to be between 10 and 20 years. The freedoms from structural valve failure are $70 \%$ to $90 \%$ at 10 years and $50 \%$ to $80 \%$ at 15 years, but substantially less in younger patients. ${ }^{17}$

Bicuspid aortic valve malformations typically calcify earlier and more intensively than do archetypal aortic valves, are often associated with ascending aortic wall pathology, and are considered a contraindication for percutaneous or transapical replacement. It is estimated these valves represent more than $50 \%$ of all aortic stenosis cases in industrialized societies, ${ }^{18}$ and operative therapy will clearly remain the treatment of choice for the foreseeable future.

The risk-benefit ratio of transcatheter valves for high-risk patients (Society of Thoracic Surgeons score $>10 \%$ ) with less than 5 years of life expectancy could be acceptable. ${ }^{19}$ For this population of patients, current studies ${ }^{20}$ suggest that mortality and short-term morbidity could be competitive with conventional surgery, although the exact relevance of these studies remains to be established.

Finally, extension of transcatheter aortic valve indications to younger patients who are candidates for mechanical valve replacement would increase the potential for a "valve-invalve" replacement or other experimental procedures. The demonstration of safety and efficacy of these procedures may require substantial additional time and very likely cannot be repeated more than once. It should be noted that even in the elderly population, conventional reoperative valvular surgery has been performed with less than $11 \%$ mortality. ${ }^{21}$ For catheter-delivered valves, transfemoral and transapical approaches both require rapid ventricular pacing, critical anesthetic management of hypotension and arrhythmias during beating-heart valve implantation, and transesophageal echocardiography. Although transcatheter aortic valve 
insertion may become a valuable therapeutic option for highrisk patients with severe aortic stenosis and short life expectancy, it will still carry considerable risk. ${ }^{22}$ In the best case, wider application of transcatheter aortic valve implantation will require much more time and additional study, including head-to-head comparisons with conventional valve replacement and apicoaortic bypass in diverse risk populations.

Those familiar with heart valve history will remember that many new designs had encouraging early performance, leading to erroneous projections of durability and patient benefits. In fact, only a few valves have withstood the test of time, and patients unfortunate enough to have received less safe and effective prostheses paid the price in mortality, morbidity, and additional surgery. It is also worth remembering that failed valve designs far outnumber those that proved successful.

In response to approvals for catheter-delivered valve devices and other concerns, health authorities in Belgium have recently expressed specific recommendations: "Today, reimbursement of percutaneous aortic valves cannot be defended because of the many unsolved questions regarding safety of patients and the lack of a target population. Published data are not convincing regarding the fact that the risk associated with the procedure of percutaneous valve implant could be less than the regular surgical procedure.... The high mortality at 6 months questions the safety of this procedure. The medical community should be well informed on the fact that the CE mark does not indicate a device is safe for clinical use." 23

Whereas large financial investments presently involved in transcatheter valve delivery technologies are devoted to the elderly population, little recently has been done for the much larger population of younger patients and children worldwide who need a durable heart valve substitute that performs safely without warfarin anticoagulation. ${ }^{24}$ It is probable that catheter-based valve technology will result in an attractive option for a specific segment of the valve replacement population. We believe, however, that it is also important for industry to focus on development of improved devices for the great majority of patients needing valve replacement. As we have all known, it is difficult to make something simple.

\section{References}

1. Rabelais F. Gargantua and Pantagruel. Urquhart T, Le Motteux, translators. New York: Random House; 1994.

2. Lund O, Bland M. Risk-corrected impact of mechanical versus bioprosthetic valves on long-term mortality after aortic valve replacement. J Thorac Cardiovasc Surg. 2006;132:20-6.

3. Stassano P, Di Tommaso L, Monaco M, Iorio F, Pepino P, Spampinato N, et al. Aortic valve replacement: a prospective randomized evaluation of mechanical versus biological valves in patients ages 55 to 70 Years. J Am Coll Cardiol. 2009;54:1862-8.

4. Tabata M, Umakanthan R, Cohn L, Bolman RM, Shekar PS, Chen FY, et al. Early and late outcomes of 1000 minimally invasive aortic valve operations. Eur J Cardiothorac Surg. 2008;33:537-41.

5. Zilla P, Brink J, Human P, Bezuidenhout D. Prosthetic heart valves: catering for the few. Biomaterials. 2008;29:385-406.

6. Scotten LN, Walker DK. New laboratory technique measures projected dynamic area of prosthetic heart valves. J Heart Valve Dis. 2004;13:120-33.

7. Wolf LG, Choudhary BP, Abu-Omar Y, Taggart DP. Solid and gaseous cerebral microembolization after biologic and mechanical aortic valve replacement: investigation with multirange and multifrequency transcranial Doppler ultrasound. J Thorac Cardiovasc Surg. 2008;135:512-20.

8. Bluestein D, Chandran KB, Manning KB. Towards non-thrombogenic performance of blood recirculating devices. Ann Biomed Eng. 2010;38:1236-56.

9. Govindarajan V, Udaykumar HS, Chandran KB. Two-dimensional simulation of flow and platelet dynamics in the hinge region of a mechanical heart valve. Ann Biomech Eng. 2009;131. 031002.

10. Dasi LP, Simon HA, Sucosky P, Yoganathan AP. New frontiers in biomedical engineering. Fluid mechanics of artificial heart valves. Clin Exp Pharmacol Physiol. 2009;36:225-37.

11. Mack M. Fool me once, shame on you; fool me twice, shame on me! A perspective on the emerging world of percutaneous heart valve therapy. J Thorac Cardiovasc Surg. 2008;136:816-9.

12. Leriche R. Philosophie de la chirurgie. Paris, France: Flammarion; 1951:267.

13. Lillehei CW. New ideas and their acceptance. As it has related to preservation of chordae tendinea and certain other discoveries. J Heart Valve Dis. 1995;4(Suppl 2):S106-14.

14. Bonow RO, Carabello BA, Chatterjee K, de Leon AC, Faxon DP, Freed MD, et al 2008 Focused update incorporated into the ACC/AHA 2006 guidelines for the management of patients with valvular heart disease: A report of the American College of Cardiology/American Heart Association task force on practice guidelines (writing committee to revise the 1998 guidelines for the management of patients with valvular heart disease): endorsed by the Society for Cardiovascular Anesthesiologists, Society for Cardiovascular Angiography and Interventions, and Society of Thoracic Surgeons. Circulation. 2008;118:e523-661.

15. Piper C, Hering D, Kleikamp G, Korfer R, Horstkotte D. Valve replacement in octogenarians: arguments for an earlier surgical intervention. J Heart Valve Dis. 2009;18:239-44.

16. Chen E, Sapirstein W, Ahn C, Swain J, Zuckerman B. Perspective on clinical trial design for cardiovascular devices. Ann Thorac Surg. 2006;82:773-5.

17. Siddiqui RF, Abraham JR, Butany J. Bioprosthetic heart valves: modes of failure. Histopathology. 2009;55:135-44.

18. Zegdi R, Achouh P, Fabiani JN. Percutaneous aortic valve replacement with the CoreValve bioprosthesis. J Thorac Cardiovasc Surg. 2008;135:1407-8.

19. Vahanian A, Alfieri O, Al-Attar N, Antunes M, Bax J, Cormier B, et al. Transcatheter valve implantation for patients with aortic stenosis: a position statement from the European Association of Cardio-Thoracic Surgery (EACTS) and the European Society of Cardiology (ESC), in collaboration with the European Association of Percutaneous Cardiovascular Interventions (EAPCI). Eur J Cardiothorac Surg. 2008;34:1-8

20. Chiam P, Ruiz CE. Percutaneous transcatheter aortic valve implantation: assessing results, judging outcomes, and planning trials: the interventionalist perspective. JACC Cardiovasc Interv. 2008;1:341-50.

21. Maganti M, Rao V, Armstrong S, Feindel CM, Scully HE, David TE. Redo valvular surgery in elderly patients. Ann Thorac Surg. 2009;87:521-5.

22. Walther T, Dewey T, Borger MA, Kempfert J, Linke A, Becht R, et al. Transapical aortic valve implantation: step by step. Ann Thorac Surg. 2009;87:276-83.

23. Van Brabandt H, Neyt M. Safety of percutaneous aortic valve insertion. A systematic review. BMC Cardiovasc Disord. 2009;9:45.

24. Takkenberg JJ, Rajamannan NM, Rosenhek R, Kumar AS, Carapetis JR, Yacoub $\mathrm{MH}$, et al. The need for a global perspective on heart valve disease epidemiology. The SHVD working group on epidemiology of heart valve disease founding statement. J Heart Valve Dis. 2008;17:135-9. 